\title{
Cromobacteriose em Ilhéus, Bahia: investigação epidemiológica clínica e laboratorial
}

\author{
Chromobacteriosis in Ilhéus, Bahia: epidemiologic, \\ clinical and laboratorial investigation
}

\author{
Juarez P. Dias ${ }^{1}$, Célia Silvany ${ }^{2}$, Maria M. Saraiva ${ }^{1}$, Hilda R. Ruf ${ }^{1}$, \\ Julio D. Guzmán ${ }^{3}$ e Eduardo H. Carmo ${ }^{4}$
}

\begin{abstract}
RESUMO
Em abril/2004, um grupo de pessoas realizou passeio a um sítio em cidade no baixo sul da Bahia e em seguida três adolescentes de uma mesma família apresentaram septicemia grave com óbito de dois destes. Objetivando identificar o evento, o Serviço de Vigilância procedeu à investigação epidemiológica, clínica, laboratorial e ambiental, identificando a Chromobacterium violaceum em material biológico de um dos pacientes que evoluíram para óbito e na água e solo do local do passeio. Esta é o primeira descrição desta doença na Bahia.
\end{abstract}

Palavras-chaves: Investigação epidemiológica. Surto. Cromobacteriose. Chromobacterium violaceum.

\section{ABSTRACT}

In April/2004, a group of people traveled to a farm in a town in the south of Bahia and afterwards, three teenagers from the same family developed symptoms of severe septicemia and two died. The Health Department carried out an epidemiologic, clinical, laboratory and environmental investigation that resulted in the identification of Chromobacterium violaceum, in biological material from one of them, water and soil. This is the first report of the disease in Bahia State.

Key-words: Epidemiologic investigation. Outbreak. Chromobacteriosis. Chromobacterium violaceum.

Chromobacterium violaceum é um microorganismo de vida livre do solo e da água ${ }^{7}$ de regiões tropicais e subtropicais, onde as condições ambientais de temperatura são ideais para o seu desenvolvimento ${ }^{12}$. Trata-se de bastonete Gram negativo, móvel, anaeróbio facultativo, que cresce nos meios usuais e as colônias normalmente produzem um pigmento violáceo não difusível e raramente apresentam colônias não pigmentadas ${ }^{18}$.

As primeiras descrições sobre a agressão da Chromobacterium violaceum foram feitas por Wooley, em búfalos nas Filipinas em $1905^{22}$ e em humanos, por J.E. Lesslar, na Malásia em $1927^{19}$. As infecções em animais são mais freqüentes, sendo relatados casos em porcos ${ }^{9}$, cães ${ }^{5}$ e raras em humanos, embora, quando ocorra, provoque quadros septicêmicos graves que normalmente levam ao óbito ${ }^{2}$.

A contaminação geralmente se dá por meio de solução de continuidade da pele ${ }^{8}$ em contato com águas estagnadas ${ }^{15}$ havendo também relatos de casos após afogamento ${ }^{4}$. 0 período de incubação pode variar de três a quatorze dias, de acordo com o tipo de exposição $0^{813}$, sendo os principais sinais/ sintomas: febre, náuseas, vômitos e dor abdominal intensa ${ }^{2}{ }^{12}$, associado a abscesso em pele, celulite, pústulas, linfadenite e osteomielite $^{212} 20$. Há relato de quadros septicêmicos graves associado a múltiplos abscessos em fígado, baço, pulmão, linfonodos, pele e mais raramente em cérebro, evoluindo para toxemia, confusão mental, choque e morte ${ }^{2611}$. A taxa de letalidade é bastante elevada, sendo em torno de $41 \%$, no período de 1980 a 1994, nos Estados Unidos ${ }^{12}$. Esta gravidade da doença deve-se a uma endotoxina produzida pela bactéria ${ }^{13}$, condicionada por uma deficiência imunológica do paciente principalmente a doença crônica granulomatosa ${ }^{1}$.

A doença se distribui principalmente em região tropical e subtropical, entre as latitudes $35^{\circ} \mathrm{N}$ e $35^{\circ} \mathrm{S}$ da linha do Equador ${ }^{13}$. A maior frequiência é observada no Sudeste Asiático e Oceania ${ }^{26}$. Nas Américas foram descritos casos nos Estados

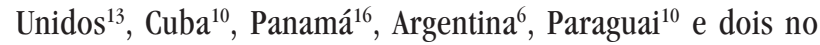
Brasil: um na região do Rio Negro ${ }^{14}$ e outro em São Paulo ${ }^{11}$.

\footnotetext{
1. Secretaria da Saúde do Estado da Bahia, Salvador, BA. 2. Obras Sociais Irmã Dulce de Salvador, Salvador, BA. 3. Secretaria Municipal de Saúde de Ilhéus, Ilhéus, BA 4. Secretaria de Vigilância em Saúde do Ministério da Saúde, Brasília, DF.

Endereço para correspondência: Dr. Juarez Pereira Dias. Av. Sete de Setembro 2493/404, Bairro Vitória, 40080-003 Salvador, BA

Telefax: $55713115-8333$

e-mail: jucadias09@uol.com.br

Recebido para publicação em 5/11/2004

Aceito em 26/7/2005
} 
Este artigo se propõe a descrever um episódio de cromobacteriose ocorrido em um município da região sul do Estado da Bahia.

\section{MATERIAL E MÉTODOS}

Trata-se de estudo descritivo de um surto de doença septicêmica grave ocorrida em três adolescentes de uma mesma família, após participarem de um evento recreativo. Neste trabalho, serão abordados os aspectos clínicos dos casos e as etapas da investigação epidemiológica e laboratorial, tanto humana como ambiental, destacando a evolução dos pacientes e o tratamento daquele que apresentou cura.

o evento. Em 21/04/2004 um grupo de aproximadamente, 60 indivíduos, predominantemente adolescente, realizou um passeio a um sítio, localizado às margens de uma Rodovia no município de Ilhéus, situado na região sul do Estado da Bahia, onde existia a presença de um pequeno lago formado pelo escoamento de águas pluviais. Este local, habitado por um casal de caseiros e dois filhos menores, há muitos anos é utilizado pela comunidade para atividades religiosas e de lazer, não havendo relato de doenças associadas ao seu uso. Alguns dias após o passeio, três irmãos, dentre os integrantes deste grupo, passaram a apresentar quadro septicêmico grave, sendo internados para esclarecimento diagnóstico.

Investigação epidemiológica e ambiental. Após a ocorrência dos casos, a equipe médica responsável pela assistência, suspeitou de quadro septicêmico grave e solicitou avaliação por infectologista, avisando o Serviço de Vigilância Epidemiológica do Município, que iniciou a investigação do evento. Inicialmente procedeu-se entrevista com os responsáveis pelos pacientes, tentando identificar os aspectos semelhantes no que diz respeito ao quadro clínico, fontes comuns de exposições e fatores predisponentes. Ao mesmo tempo, procurou-se obter da equipe médica, dos locais onde os doentes foram ou estavam sendo atendidos, as hipóteses diagnósticas e resultados laboratoriais. Posteriormente, desenvolveram-se gestões junto ao Departamento de Policia Técnica do Instituto Médico Legal Nina Rodrigues, Regional Ilhéus, da Secretaria de Segurança Publica do Estado da Bahia, com a prévia autorização da família, para a realização de necropsia em um dos casos que evoluiu para óbito.

Em posse das informações disponíveis, formulou-se a definição inicial de caso, como sendo todo aquele participante do passeio ao sítio X em 21/04/2004, que apresentasse febre. Posteriormente, a definição de caso foi mais restrita, considerando-se apenas aqueles que além de terem participado do passeio, apresentasse febre acompanhada de dor abdominal e/ou desconforto respiratório. Com esta definição, todos os participantes do passeio foram convocados para atendimento no Hospital Regional de Referência, visando identificação de novos casos.

Foram coletadas amostras sanguíneas dos indivíduos inicialmente classificados como caso para exames sorológicos e do segundo óbito, fragmentos de vísceras e secreção purulenta do pulmão para serem encaminhadas para estudo anatomopatológico e cultura bacteriológica. Em um dos adolescentes e nos seus pais foram realizados os seguintes exames: dosagem de G6PD, pesquisa de HIV1e 2, VDRL, shistossomina ID, sorologia para brucelose, objetivando identificar doenças associadas que indicassem imunodeficiência.

Do meio ambiente, entre 07/05 e 17/06, foram coletadas as seguintes amostras, para exames bacteriológicos ${ }^{37}$ : a) No sítio $\mathrm{X}$ - seis amostras de água do lago e seis de solo da sua margem, uma da cisterna e quatro de solo distante do lago b) $\mathrm{Na}$ vizinhança da residência dos casos - duas da cisterna e três do solo; c) No sítio Y, onde os adolescentes haviam freqüentado 15 dias antes de adoecerem - uma amostra de solo, amostras de sangue, secreção pulmonar e ambientais foram encaminhadas para serem processadas no Laboratório Central de Saúde Pública Prof. Gonçalo Moniz (LACEN/BA), sendo as cepas isoladas encaminhadas ao Departamento de Bacteriologia do Laboratório de Enterobactérias da FIOCRUZ/RJ para confirmação feno e genotípica. As vísceras foram enviadas ao Centro de Pesquisas Gonçalo Moniz da FIOCRUZ/BA.

\section{RESULTADOS}

No terceiro dia após o passeio, um menor de 12 anos passou a apresentar otalgia, otorréia, dor de garganta e abdominal intensa, sendo internado três dias depois com quadro de septicemia. Os exames laboratoriais revelaram leucopenia e a radiografia de tórax infiltrado em ambos os pulmões. Fez uso de antibióticos, entretanto apresentou piora do quadro, evoluindo para óbito em 28/04. Neste mesmo dia, em seu irmão de 14 anos, surgiu cefaléia, febre, vômitos, dispnéia, tumoração na região cervical e massa palpável em flanco direito, sendo internado para esclarecimento diagnóstico. Os exames evidenciaram leucocitose e elevação de transaminases; a ultra-sonografia abdominal revelou hepatomegalia e a radiografia de tórax imagens irregulares de condensação disseminada em ambos os pulmões. Apesar do uso de vários antibióticos, evoluiu para óbito dois dias depois. Em 28/04, o outro irmão de 9 anos foi internado com cefaléia, vômitos, febre e dor abdominal e presença de múltiplos abscessos pelo corpo. Os exames hematológicos evidenciaram leucocitose, enquanto que a ultra-sonografia e a tomografia computadorizada de abdômen revelaram hepatomegalia e a radiografia apresentava tórax com imagens de condensação no hemitórax direito. Foram substituídos os antibióticos em uso pelo Meropenen, durante seis semanas. A opção terapêutica inicialmente se deu pela suspeita clínica de melioidose e em seguida pelo resultado bacteriológico em secreção do pulmão de irmão que foi a óbito. 0 antibiótico foi utilizado por seis semanas, ocorrendo a alta por cura em 14/06.

$\mathrm{Na}$ inspeção ao local do passeio, verificou-se que o sítio possuía aproximadamente $300 \mathrm{~m}^{2}$, com algumas árvores frutíferas e uma residência que dispunha de fossa séptica e poço artesiano de onde era retirada água para consumo. Observou-se a presença de alguns eqüinos, caninos, felinos e aves domésticas. Próximo a casa, em uma área gramada, destacava-se a existência de um pequeno lago, formado exclusivamente por águas pluviais, que 
nesta época do ano apresentava-se bastante cheio devido a intensas chuvas que ocorriam na região. A sua água tinha a coloração verde escuro, devido possivelmente a grande quantidade de matéria orgânica, e apresentava odor ferruginoso. A sua profundidade máxima não excedia $1 \mathrm{~m}$ e o seu leito é arenoso e lodoso em alguns pontos, com a presença de vegetação higrófila nas margens e alguns pontos no fundo. Durante a inspeção foi observada a presença de lixo doméstico constituído de material descartável, e de fezes de eqüinos em torno do lago.

A residência dos três casos índices estava situada em bairro de classe média baixa em rua sem calçamento, na sede do mesmo município onde ocorreu o evento. A residência possuía paredes de alvenaria, cobertura de telha e boas instalações sanitárias. A água para consumo provinha de cisterna, apesar da cidade dispor de rede do Sistema Público de Abastecimento.

Dentre os demais participantes do passeio (57 pessoas), todos se apresentavam assintomáticos ou com discreta cefaléia e/ou febrícula, sendo que 21 permaneceram em observação por 24h. Após avaliação clínica e coleta de exames laboratoriais, todos foram liberados para domicílio com prescrição de medicamentos sintomáticos e orientados a retornar a Unidade de Saúde, caso persistisse a sintomatologia ou surgimento de novos sinais e/ou sintomas. Desta forma, após a restrição na definição de caso, foram identificados apenas os três irmãos.

Os exames sorológicos (MacElisa) realizados para leptospirose foram todos negativos. Do segundo óbito, tanto o laudo de necropsia como o exame anátomo-patológico evidenciou múltiplos focos de abscessos em pulmão, fígado e baço, e da secreção pulmonar foi isolada Chromobacterium violaceum e Klebsiella pneumoniae. Os demais exames realizados no adolescente e nos pais apresentaram resultados negativos.

A Chromobacterium violaceum foi identificada no meio ambiente em quatro amostras de água do lago e em seis do solo situado as suas margens no sítio X. Nos demais locais de coleta não foi isolado esta bactéria.

Como medida de precaução ao surgimento de novos casos, o sítio $\mathrm{X}$ foi interditado para qualquer atividade de lazer ou religiosa, até a finalização do estudo de impacto ambiental para identificação de pontos de riscos.

\section{DISCUSSÃO}

A comunicação à Vigilância Epidemiológica da existência de casos e óbito, em uma mesma família, de adolescente previamente sadio, de uma doença desconhecida, desencadeou o processo de investigação que se iniciou sem uma hipótese etiológica clara para o evento. Inicialmente suspeitou-se de leptospirose, em parte devido as fortes chuvas que ocorriam na região e a presença de roedores, o que foi descartado pelo exame sorológico negativo para esta doença. Suspeitou-se também de intoxicação por agrotóxico, hipótese eliminada pelo depoimento do caseiro que não referia uso destes produtos no local. Posteriormente, a partir das evidências clínicas do quadro septicêmico, corroborado pelos achados de necropsia do segundo óbito, suspeitou-se de infecção por bactéria gram negativa, dentre estas a Burkhoderia pseudomallei, agente etiológico da melioidose, já que as manifestações clínicas eram bastante semelhantes $^{311}$. 0 isolamento da Chromobacterium violaceum no meio ambiente levou a forte suspeita de ser esta bactéria o possível agente etiológico envolvido no episódio. A Klebsiella pneumoniae identificada, possivelmente deveu-se a infecção hospitalar, uma vez que esta bactéria é um dos patógenos mais frequentemente encontrado em pacientes com infecção respiratória nosocomial ${ }^{21}$.

Pelo quadro clínico apresentado, resultados de exames laboratoriais e de imagens, laudo de necropsia, achados anatomopatológicos e isolamento da Chromobacterium violaceum na secreção do pulmão do segundo caso que foi á óbito, são evidências suficientes que nos permite classificar como cromobacteriose humana, sendo os outros dois membros da família, que também adoeceram considerados como caso pelo vínculo epidemiológico. No momento estão sendo realizadas análises para identificação genotípica das bactérias isoladas do humano e do meio ambiente, água e solo, com o objetivo de estabelecer o elo entre as mesmas.

A infecção pela Chromobacterium violaceum é um evento raro, apesar desta bactéria estar presente no solo e água de áreas tropicais e subtropicais, nas quais grande parte do território brasileiro está inserido. Possivelmente os adolescentes se contaminaram por meio do contato com a água estagnada do lago, como relatado por Ponte e Jenkins ${ }^{15}$. A faixa etária é compatível com o descrito pela literatura, que considera a doença do âmbito da pediatria ${ }^{17}$ Apesar da descrição da associação da doença com deficiência imunitária, doença granulomatosa crônica, diminuição do número de células T, e ao vírus da imunodeficiência adquirida ${ }^{13}{ }^{17}$, os exames realizados, até o momento, no caso sobrevivente e em seus pais não revelaram esta condição. 0 quadro clínico apresentado assim como os exames hematológicos, ultrasonografia, tomografia computadorizada de abdômen e radiografia de tórax e o laudo do exame cadavérico realizado no segundo óbito apresentaram achados também encontrados por Midani ${ }^{12}$ e Chen ${ }^{2}$ Os cortes histológicos com presença de múltiplas coleções de piócitos e grumos bacterianos em área necrosada demonstram a agressividade e virulência da bactéria em provocar quadros graves. Esta doença, quando precocemente identificado e conveniente e oportunamente tratados aumentam em sobremaneira a sobrevida do paciente ${ }^{13}$ Para que isso ocorra é de fundamental importância que a investigação epidemiológica seja conduzida de forma rápida, integrada para que possa dar respostas imediatas que controlem o evento e evite o surgimento de novos casos. Acredita-se que a sobrevivência desse último paciente deve-se em muito as conclusões advindas da investigação epidemiológica e laboratorial que nortearam o sucesso das condutas terapêuticas instituídas pela equipe médica. 


\section{REFERÊNCIAS BIBLIOGRÁFICAS}

1. Bradley DB, Jonhson LW. Recurrent nonfatal Chromobacterium violaceum infection in a nonimmunocompromised patient. Infections in Medicine 17:686-689, 2000

2. Chen CH, Lin LC, Liu CE, Young TG. Chromobacterium violaceum bacteremia: a case report. Journal of Microbiology Immunology and Infection 36:141-144, 2003.

3. Dance DAB. Melioidosis. In: Guerrant RL, Walker DH, Weller PF (eds) Tropical Infectious Diseases. Principles, Pathogens and Practice, Philadelphia, USA, p.430-437, 1999.

4. Ender PT, Dolan MJ. Pneumonia associated with near-drowning. Clinical Infectious Disease 25: 896-907, 1997.

5. Gogolewiski RP. Chromobacterium violaceum septicaemia in a dog. Australian Veterinary Journal 60: 226, 1983.

6. Kaufman SC, Ceraso D, Schugurensky A. First case report from Argentina of fatal septicemia caused by Chromobacterium violaceum. Journal of Clinical Microbiology 23:956-958, 1986.

7. Koburger JA, May SO. Isolation of Chromobacterium violaceum spp. from foods, soil and water. Applied and Environmental Microbiology 44:14631465,1982

8. Lee J, Kim JS, Nahm CH, Choi JW, Kim J, Pai SH, Moon KH, Lee K, Chong Y. Two Cases of Chromobacterium violaceum Infection after injury in a Subtropical Region. Journal of Clinical Microbiology 37:2068-2070, 1999.

9. Liu CH, Chu RM, Wing CN, Lin YL, Chi CS. An acute pleuropneumonia in a pig caused by Chromobacterium violaceum Journal of comparative pathology 100:459-463, 1989.

10. Martinez C, Condino-Neto A, Moran M e Arbo A. Niña de 4 años con historia de neumonía y ectima. Lagid Boletín capturado no site: http://www.lagid.lsuhsc.edu/Casos/971-012.htm em 20/09/2004.
11. Martinez R, Velludo MASL, Santos VR, Dinamarco PV. Chromobacterium violaceum Infection in Brazil. A case report. Revista do Instituto de Medicina Tropical de São Paulo 42:111-113, 2000.

12. Midani S, Rathore M. Chromobacterium violaceum. Infection. Southern Medical Journal 91:464-466, 1998.

13. Moore CC, Lane JE, Stephens JL. Successful treatment of an infant with Chromobacterium violaceum sepsis. Clinical Infectious Disease 32:E107-110, 2001 .

14. Petrillo VF, Severo V, Santos MM. Edelweiss EL. Recurrent infection with Chromobacterium violaceum: first case report from South America. The Journal of Infectious Disease 9:167-169, 1984.

15. Ponte R, Jenkins SG. Fatal Chromobacterium violaceum infections associated with exposure to stagnant waters. Pediatric Infectious Disease Journal 11: 583-586, 1992.

16. Ríos CD, Delgado S, Cisternas 0. Septicemia por Chromobacterium violaceum. Revista Hospital Niño (Panamá) 5: 22-25, 1985.

17. Sirinavin S, Techasaensiri C, Benjaponpitak S, Pornkul R, Vorachit M. Invasive Chromobacterium violaceum infection in children: Case report and review. The Pediatric Infectious Disease Journal 24:559-561, 2005

18. Sivendra R, Tan SH. Pathogenicity of Nonpigmented Cultures of Chromobacterium violaceum. Journal of Clinical Microbiology 5:514-516, 1977.

19. Sneath PHA, Whelan JPF, Singh RB, Edward D. Fetal infection by Chromobacterium violaceum. Lancet II:276-277,1956.

20. Tucker RE, Winter WG, Wilson HD. Osteomyelitis associated with Chromobacterium violaceum sepsis. The Journal of Bone and Joint Surgery America 61:949-951, 1979.

21. Wey SB. Infecções Hospitalares: Princípios Gerais para Prevenção e Controle. In: Veronesi R, Focaccia R (eds) Tratado de Infectologia, $2^{\text {a }}$ edição, São Paulo, p.768-792, 2002.

22. Wooley PG. Bacillus violaceum manilae (a pathogenic organism). Bulletin of the Johns Hopkins Hospital 16:89,1905. 